\title{
Myoclonus associated with treatment with high doses of morphine: the role of supplemental drugs
}

\author{
Julia M Potter, Donald B Reid, Rosalie J Shaw, Peter Hackett, Peter E Hickman
}

\section{Department of \\ Pharmacology, University of Western Australia, Nedlands, Western Australia 6009 \\ Julia M Potter, MB, senior lecturer}

Hospice Care Service, Silver Chain, Osborne Park, Western Australia 6017

Donald B Reid, FRACGP, medical director

Palliative Care Unit, Repatriation General Hospital (Hollywood), Nedlands, Western Australia 6009

Rosalie J Shaw, FRACMA, director

Combined Unit in Clinical Pharmacology and Toxicology, State Health Laboratories and University of Western Australia, Nedlands Western Australia 6009

Peter Hackett, AAIMLS, senior technologist

\section{Department of}

Biochemistry, Royal Perth Hospital, Perth, Western Australia 6000

Peter E Hickman, FRCPA, clinical biochemist

Correspondence to: Dr Julia M Potter, Department of Clinical Pharmacology, Princess Alexandra Hospital, Brisbane, Queensland 4102.

\section{Abstract}

Objective-To estimate the prevalence of important side effects in patients with malignant disease who were receiving high doses of morphine as part of their palliative treatment.

Design-Data on patients were collected over 12 months.

Setting-Two palliative care units in Western Australia.

Patients - 19 Patients with malignant disease who were receiving morphine either subcutaneously or orally as the main analgesic. 10 Patients receiving a total daily dose of morphine of at least $500 \mathrm{mg}$ orally or $250 \mathrm{mg}$ parenterally were enrolled in the study. The other 9 patients were enrolled after an important problem thought to be related to the morphine had been identified. All of the patients were taking drugs to supplement the treatment.

Interventions-The dose of morphine or route of administration, or both, was changed in three patients.

Main outcome measure-Determination of the prevalence of side effects in the patients. Assessment of the relation of any side effects with the supplemental drugs taken by the patients.

Main results-Plasma morphine and electrolyte concentrations were measured and a full history taken for each patient. Thirteen of the 19 patients had an important side effect; 12 of them had myoclonus and one had hyperalgesia of the skin. Plasma morphine concentrations were similar in patients with and without myoclonus, ranging from 158 to $3465 \mathrm{nmol} / \mathrm{l}$ and 39 to $2821 \mathrm{nmol} / 1$ respectively. Eight of the patients with side effects were taking an antipsychotic drug concurrently compared with none of those without side effects. A greater proportion of patients with side effects were taking the antinauseant drug thiethylperazine $(6 / 13 v 2 / 6)$ and at least one non-steroidal anti-inflammatory drug $(10 / 13 v 2 /$ 6), whereas a smaller proportion were taking a glucocorticosteroid $(3 / 13 v 4 / 6)$. The estimated prevalence of important side effects in the total population of patients receiving palliative treatment in the two units was $2 \cdot 7 \cdot 3 \cdot 6 \%$.

Conclusions - Myoclonus as a side effect of treatment with morphine is more likely to occur in patients taking antidepressant or antipsychotic drugs as antiemetics or as adjuvant agents or non-steroidal anti-inflammatory drugs for additional analgesia. If a patient develops myoclonus the best approach may be to change the supplemental treatment.

\section{Introduction}

In patients with advanced malignant disease high doses of opiates may be necessary to relieve pain and thus improve the quality of life. Although doctors recognise that side effects are more probable in patients receiving such treatment long term, there are few reports of those effects. Among the effects are the excitatory responses that have been described for pethidine, which vary from mild nervousness and change of mood to multifocal myoclonus.' We had gained the impression that these unwanted effects occur with other opiates and are more common than appreciated or reported by either patients or their attendants. The possible roles of precipitating or accompanying factors are not well understood, although norpethidine accumulates in patients receiving high doses of pethidine long term, ${ }^{1}$ particularly in those with renal impairment, ${ }^{2}$ and a possible role of phenothiazines was indicated in a recent study. ${ }^{3}$

After one of us (DBR) observed myoclonus in three patients over a short time we studied the occurrence and nature of the more serious side effects in patients receiving high doses of morphine as the primary opiate in their palliative treatment.

\section{Methods}

Table I gives the patients' details and clinical data. All of them (10 men and nine women aged 38-70) had malignant disease and were receiving morphine as the main analgesic: nine subcutaneously through a constant infusion syringe pump and eight orally on a fixed time schedule; the remaining two were studied when the route of administration was changed.

We collected samples and data over 12 months from patients in the hospice care service or the palliative care unit. Those patients (10) receiving a total daily dose of morphine of at least $500 \mathrm{mg}$ orally or $250 \mathrm{mg}$ parenterally were enrolled in the study. Other patients (9) were enrolled after an important problem thought to be related to the opiate had been identified. The study was approved by the human rights committee of the University of Western Australia and the ethics committees of the other participating organisations. All patients or their immediate relatives gave informed consent.

We obtained a venous blood sample from all of the patients to measure plasma morphine and electrolyte concentrations. At the same time a full history was taken, which included a complete drug history and the presence of symptoms likely to be side effects, their nature, the time of their onset, and their duration. Morphine concentrations (unconjugated) were measured by high performance liquid chromatography by a modification of the method of Logan et al, ${ }^{4}$ and electrolyte concentrations were measured with an autoanalyser (Technicon, Australia).

\section{Results}

Thirteen of the 19 patients had important side effects (table I). The main effect was myoclonus, which occurred in 12 of the patients, one of whom also had increased sweating. One patient had pronounced hyperalgesia of the skin. The myoclonus was usually described as uncontrollable jerks, affecting the arms (four patients), legs (three), or both arms and legs (five), the duration of the spasms being commonly about one second. The jerks were not symmetrical, and when they occurred in the arms and legs the effect was more apparent in the arms (four patients). Their frequency varied widely among the patients (from once or twice a day to every 10 minutes), and they occurred 
at different times. The frequency was not related to the overall plasma morphine concentration, but patients related the onset of the jerks and any subsequent increase in their frequency to increases in dose (five patients) or the introduction of the morphine pump or increase in dose (one patient). Jerking occurred during the day and the night; three patients said that it was worse at night and one that it prevented sleep.

The jerking first occurred in one patient (case 16) during the study when an increase in the dose of morphine and a slight increase in her plasma morphine concentration coincided with a reduction in the dose of oxycodone and the introduction of indomethacin and piroxicam. In most of the patients jerking had been present for weeks or months (nine months in one patient (case 1)). Generally, in patients in whom the frequency of jerks was low episodes of jerking had not been seen by doctors or nurses before the study, nor had their presence been mentioned; patients and their relatives had assumed that the jerks were a consequence of the treatment and that they accompanied improved analgesia. As such, many of the patients regarded them as a "small price to pay." Two of the patients, however, said that the jerks were worrying; they prevented one patient sleeping: and three others noted them to be important in that they made them clumsy. In one patient who had had epilepsy induced by trauma (case 16) the myoclonus was separate and distinguishable from her epilepsy.

The plasma morphine concentrations ranged from $39 \mathrm{nmol} / 1$ to $3465 \mathrm{nmol} / \mathrm{l}$, the patients receiving daily doses of $120-1200 \mathrm{mg}$ morphine orally or $210-800 \mathrm{mg}$ by constant infusion syringe pump (table I). The concentrations were similar in the patients with myoclonus $(158-3465 \mathrm{nmol} / \mathrm{l}$, mean $768 \mathrm{nmol} / \mathrm{l}$ ) and those without myoclonus $(39-2821 \mathrm{nmol} / \mathrm{l}$, mean 804 nmol/l). The patient with hyperalgesia (case 19) had a low plasma morphine concentration.

Apart from the total daily dose and plasma concentration of morphine, other factors that were considered as possibly contributing to the myoclonus included the patients' electrolyte concentrations and drugs that they were receiving concurrently. Plasma samples were analysed for any important metabolic abnormality that may either exacerbate myoclonus induced by drugs or itself cause neuromuscular excitability. Seven patients had abnormal concentrations of electrolytes (table II), five of whom had myoclonus. Of these five, one (case 11) had appreciable hypercalcaemia $(3.76 \mathrm{mmol} / \mathrm{l})$, a condition more usually associated with muscle

TABLE I-Clinical details of patients with malignant disease who were receiving high doses of morphine

\begin{tabular}{|c|c|c|c|c|c|c|c|}
\hline Case No & $\begin{array}{l}\text { Site of primary } \\
\text { malignancy }\end{array}$ & $\begin{array}{c}\text { Age } \\
\text { (years) }\end{array}$ & Sex & $\begin{array}{c}\text { Dose of } \\
\text { morphine } \\
\text { (mg/day) }\end{array}$ & $\begin{array}{c}\text { Route of } \\
\text { administration }\end{array}$ & $\begin{array}{c}\text { Plasma } \\
\text { morphine } \\
(\mathrm{nmol} / \mathrm{l})\end{array}$ & Side effects \\
\hline 1 & Breast & 55 & $\mathrm{~F}$ & 800 & Pump & 3465 & Myoclonus \\
\hline 2 & Pancreas & 68 & $\mathrm{~F}$ & 420 & Pump & 2821 & \\
\hline 3 & Breast & 38 & $\mathbf{F}$ & 640 & Pump & $\left\{\begin{array}{l}1670 \\
1582\end{array}\right\}$ & Myoclonus \\
\hline 4 & Brain (astrocytoma) & 49 & $M$ & 300 & Pump & 1026 & \\
\hline 5 & Larynx & 67 & $M$ & 240 & Pump & 963 & Myoclonus \\
\hline 6 & Cervix & 39 & $\mathrm{~F}$ & 240 & Pump & 956 & Myoclonus \\
\hline 7 & Rectum & 58 & $\mathrm{~F}$ & 360 & Pump & 679 & \\
\hline 8 & Cervix & 70 & $\mathbf{F}$ & 600 & Pump & 571 & \\
\hline 9 & Colon & 63 & $\mathrm{~F}$ & 360 & Oral & 438 & Myoclonus \\
\hline do & Prostate & 75 & $M$ & 240 & Pump & 350 & Myoclonus \\
\hline 11 & Lung & 67 & $M$ & 150 & Oral & 333 & Myoclonus, sweating \\
\hline 12 & Skin (melanoma) & 34 & $M$ & $\left\{\begin{array}{l}540 \\
950\end{array}\right.$ & $\begin{array}{c}\text { Pump } \\
\text { Oral }\end{array}$ & $\left.\begin{array}{l}336 \\
249\end{array}\right\}$ & Myoclonus \\
\hline 13 & Colon & 53 & $M$ & 450 & Oral & $\left\{\begin{array}{l}389 \\
249\end{array}\right\}$ & Myoclonus \\
\hline 14 & Lung & 64 & $M$ & 300 & Oral & 294 & Myoclonus \\
\hline 15 & Breast & 41 & $\mathrm{~F}$ & $\begin{array}{l}\left\{\begin{array}{l}450 \\
325\end{array}\right. \\
500\end{array}$ & $\begin{array}{l}\text { Oral } \\
\text { Oral } \\
\text { Oral }\end{array}$ & $\begin{array}{r}301 \\
91 \\
147\end{array}$ & \\
\hline 16 & Cervix & 38 & $\mathrm{~F}$ & $\left\{\begin{array}{l}730 \\
210\end{array}\right.$ & $\begin{array}{l}\text { Oral } \\
\text { Pump }\end{array}$ & $\left.\begin{array}{l}182 \\
165\end{array}\right\}$ & Myoclonus \\
\hline 17 & Lung & 40 & $M$ & 1200 & Oral & $\begin{array}{l}189 \\
137\end{array}$ & \\
\hline 18 & Prostate & 53 & M & 330 & Pump & $\left\{\begin{array}{l}158 \\
172\end{array}\right\}$ & Myoclonus \\
\hline 19 & Prostate & 67 & $M$ & 120 & Oral & 39 & Hyperalgesia \\
\hline
\end{tabular}

TABLE II - Incidence of abnormal plasma electrolyte concentrations in patients with malignant disease who were receiving high doses of morphine. Figures are numbers of patients (electrolyte concentrations)

\begin{tabular}{lcc}
\hline $\begin{array}{c}\text { Abnormality in } \\
\text { electrolyte } \\
\text { concentration }\end{array}$ & $\begin{array}{c}\text { Patients with important } \\
\text { side effects } \\
(\mathrm{n}=13)\end{array}$ & $\begin{array}{c}\text { Patients without } \\
\text { important side effects } \\
(\mathrm{n}=6)\end{array}$ \\
\hline Hyponatraemia & $\begin{array}{c}2 \text { (Sodium } 128 \mathrm{mmol} / \mathrm{l}, \\
\left.120 \mathrm{mmol} / \mathrm{I}^{\star}\right)\end{array}$ \\
$\begin{array}{c}\text { Hypokalaemia } \\
\text { Hyponatraemia and } \\
\text { hypokalaemia }\end{array}$ & $\begin{array}{c}1(\text { Potassium } 2 \cdot 6 \mathrm{mmol} / \mathrm{l}) \\
\text { potassium } 124 \mathrm{mmo} / \mathrm{mmol} / \mathrm{l})\end{array}$ \\
$\begin{array}{c}\text { Hypercalcaemia } \\
\text { Hypernatraemia }\end{array}$ & 1 (Calcium $3 \cdot 76 \mathrm{mmol} / \mathrm{l})$ \\
Hyperkalaemia & 1 (Potassium $6.3 \mathrm{mmol} / \mathrm{l})$
\end{tabular}

^ Patient (case 19) had hyperalgesia

$\star \star$ Patient (case 4) was comatose at time of study; myoclonus had been present for several weeks before loss of consciousness.

weakness; two had hypokalaemia (with or without hyponatraemia) (cases 6 and 16), which occasionally is associated with irritability; and one (case 14) had hyperkalaemia. No abnormal magnesium concentrations were recorded and no patient had hypoglycaemia.

On average patients with side effects took the same number of drugs concurrently with morphine as those without side effects (table III) and the doses were similar. The pattern of use of the drugs, however, was different: there were disparities in the distribution of several important classes of drugs between the two groups of patients (table IV)-in particular, antidepressants and antipsychotics (phenothiazines such as chlorpromazine and butyrophenones such as haloperidol) had been taken only by patients with myoclonus or hyperalgesia of the skin (7/13). Furthermore, thiethylperazine (a phenothiazine) was taken more commonly by the patients with side effects, with four of them taking two different antinauseant drugs, two of these being adjuvant antidepressants (table III). There was also a preponderance of non-steroidal antiinflammatory drugs being taken by the patients with side effects (indomethacin four patients, naproxen two, diclofenac one, piroxicam two, aspirin one, compared with indomethacin one and naproxen one in the patients without myoclonus or hyperalgesia). Two of the patients with side effects were also taking paracetamol, as was one patient who did not have a side effect. Of the six patients who did not have myoclonus or hyperalgesia, four were taking steroids compared with only three of the 13 patients with these side effects. In one of these three patients, who was taking $15 \mathrm{mg}$ prednisolone daily, there was doubt concerning compliance with this drug.

\section{Discussion}

Myoclonus as a side effect of long term use of morphine has been assumed to be related to high doses of the drug. Our data, however, show that myoclonus can occur with widely differing plasma morphine concentrations and strongly suggest that drug intềactions with morphine contribute. In this study the concurrent use of psychotropic drugs, thiethylperazine (an antiemetic), and potent non-steroidal anti-inflammatory drugs such as indomethacin, was associated with myoclonus, while myoclonus was less common in patients taking corticosteroids. Over half of the patients with myoclonus also had predominantly minor abnormalities in plasma electrolyte concentrations.

Of our 19 patients, 13 had an important side effect (a prevalence of $68 \%$ ); 12 had myoclonus, and several of these had had it for months without reporting or observing it. It is thus an important problem for patients receiving palliative treatment. In the 12 months during which this study was carried out about 1100 patients were cared for by the two palliative care services. As well as the 13 patients reported on here a further eight with myoclonus were studied; in these 


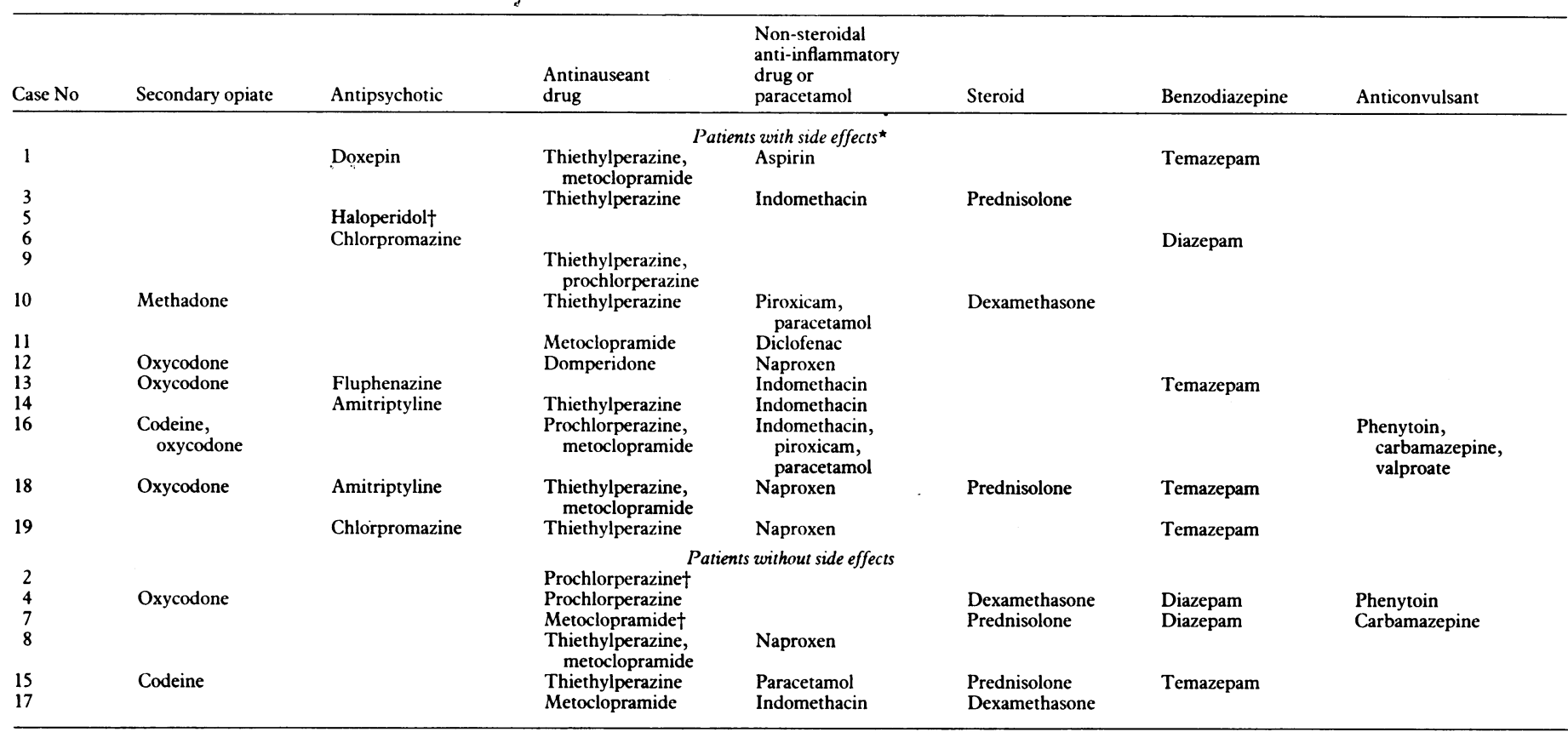

ॠMyoclonus was the side effect in all cases except case 19 , in which it was skin hypersensitivity.

†Drugs were administered through constant infusion pump.

TABLE IV-Number of patients receiving high doses of morphine with and without side effects who were taking other types of drugs

\begin{tabular}{lcc}
\hline Family of drugs & $\begin{array}{c}\text { Patients with important } \\
\text { side effects } \\
(\mathrm{n}=13)\end{array}$ & $\begin{array}{c}\text { Patients without } \\
\text { important side effects } \\
(\mathrm{n}=6)\end{array}$ \\
\hline $\begin{array}{l}\text { Antidepressants and } \\
\text { antipsychotics }\end{array}$ & $7{ }^{\star}$ & \\
$\begin{array}{l}\text { Glucocorticosteroids } \\
\text { Non-steroidal anti- }\end{array}$ & $3 \dagger$ & 4 \\
$\quad$ inflammatory drugs & 10 & 3 \\
Paracetamol & 2 & 1 \\
Antinauseant drugs & 10 & 6 \\
Anticonvulsants & 1 & 2 \\
Benzodiazepines & 5 & 2 \\
Diuretics & 3 & 2 \\
$\mathrm{H}_{2}$-antagonist & 3 & \\
${ }^{\star} \chi^{2}=5 \cdot 714 ; \mathrm{p}<0 \cdot 02$. †Compliance of one patient in doubt.
\end{tabular}

eight patients the main opiate was pethidine, methadone, or oxycodone, and myoclonus was associated with similar drug and electrolyte patterns to those reported here. We were notified of a further equivalent group of patients, but formal studies were not undertaken usually for logistic reasons. Overall, this gives a conservative estimate of the incidence of myoclonus as a side effect of treatment with an opiate as being 30-40/ $1100(2 \cdot 7-3 \cdot 6 \%)$; this is an underestimate, as only some three quarters of all patients would be receiving opiates.

Plasma morphine concentrations in the patients in this study reflected the high doses they had taken long term. Single intramuscular injections of morphine (10 $\mathrm{mg}$ ) give peak plasma concentrations of 180-250 $\mathrm{nmol} / \mathrm{l}^{\mathrm{s}}$ and trough concentrations (after four hours) of about $70 \mathrm{nmol} / \mathrm{l}$. In this study plasma was collected either before a dose was given or from patients receiving a constant infusion, whose measurements can be compared with trough concentrations. Our study did not address side effects such as respiratory depression that occur with sudden raising of plasma morphine concentrations and may occur in patients taking opiates short or long term but was concerned with side effects that present during long term maintenance treatment or attainment of a new steady state. Previous studies of side effects in patients taking opiates long term for analgesia, either postoperatively or in palliative care, have shown that high plasma concentrations of the drugs are important contributing factors. Several of the patients in this study were receiving supplemental opiates (table III), which would effectively increase their total plasma opiate concentrations. The total analgesic load would be increased further by plasma morphine-6-glucuronide concentrations. Morphine-6-glucuronide, shown recently to be analgesic, ${ }^{6}$ reaches a concentration four to five times that of morphine during long term treatment with morphine and may be more important in the analgesic effect of the treatment than morphine itself. ${ }^{7}$

In a study of patients receiving high doses of pethidine long term postoperatively accumulation of norpethidine was accompanied by excitatory side effects'; although renal impairment was directly related to accumulation of norpethidine and the occurrence of side effects, the contribution of disturbances of electrolyte or other drug concentrations was not apparent. In the present study the disturbances in electrolyte concentrations tended to be only mild or moderate and by themselves would probably not have caused the neuromuscular abnormalities. In one patient (case 16) hypokalaemia was probably associated with use of diuretics, but mild abnormalities in electrolyte concentrations, particularly sodium concentrations, are not uncommon in patients with severe disease. ${ }^{8}$

Our observation that myoclonus and hyperalgesia associated with high doses of morphine may be amplified by, or be part of, a drug interaction is important as the possible interacting agents identified in this study are all important drugs in the treatment of symptoms in modern palliative care. All patients had been receiving fairly large doses of opiates long term to relieve pain and were considered tolerant to morphine. Most of them were also receiving treatment for nausea, and some were receiving adjuvant agents such as psychotropic drugs (including tricyclic antidepressants) or additional analgesics such as non-steroidal anti-inflammatory drugs. Most of the patients in whom side effects occurred were receiving more than one drug-for example, of the seven patients taking antidepressants or antipsychotics (all with side effects), five were taking potent non-steroidal anti-inflammatory drugs, four of whom were also taking thiethylperazine. While the range of doses of drugs received by patients with and without side effects caused by opiates was not different, the total drug load was greater and the combination apparently critical in those with side effects, some of whom also had abnormal electrolyte 
concentrations. The apparent protective effect of steroids may be due to the fact that they were taken by patients not receiving other drugs in combination. For instance, myoclonus occurred in three patients taking steroids who were also receiving thiethylperazine and a non-steroidal anti-inflammatory drug.

Investigation of opioids with respect to their receptor pharmacology and neuronal function has concentrated on their primary role, which is analgesia; opiates, however, have a wider influence on spinal function. Their effect on motor neurone function is less well understood than their interaction with the autonomic nervous system, with $\alpha$ adrenergic receptor agonists producing analgesia and antagonists producing hyperalgesia. ${ }^{9}$ A similar system has been described for serotonin. ${ }^{10}$ In this study profound hyperalgesia occurred in one patient (case 19), in whom morphine concentrations were low but who was also taking thiethylperazine and chlorpromazine; both of these drugs can block the $\alpha$ adrenoceptor and serotonin receptor."

A complex interaction of opiates with the spinal motor neurones and control thereof may cause the myoclonus. In animals intravenous opiates have a biphasic, concentration dependent effect on motor neurones ${ }^{12}$; they depress polysynaptic reflexes and then apparently cause excitation. These effects are thought to be the result of opiates acting primarily on other neurones, not directly on motor neurones, ${ }^{12}$ and causing a decrease in the recurrent inhibition of motor neurones by Renshaw cells by antagonising postsynaptic glycine in a manner similar to that of strychnine." While the relevance of the very high concentrations of opiates to clinical analgesia has been questioned, ${ }^{12}$ in palliative care, particularly with opiates administered epidurally, local cerebrospinal fluid concentrations are high, and myoclonus is not uncommon. ${ }^{14}$ High morphine concentrations, however, are only one facet of the phenomenon, and the interaction with the members of the families of psychotropic and nonsteroidal anti-inflammatory drugs requires explanation. Morphine can cause or prevent convulsions depending on the dose and the type of opioid receptor population. ${ }^{15}$ It causes convulsions by stimulating the $\delta$ opiate receptors and inhibiting the GABA-ergic system, by inhibiting glycine. Furthermore, myoclonic twitches induced by enkephalin are enhanced by the dopamine antagonist haloperidol, ${ }^{116}$ and this phenomenon is probably partly responsible for the lower threshold for seizures in patients receiving phenothiazines. ${ }^{3}$ The result, as in inhibition by Renshaw cells, is increased excitation. Non-steroidal anti-inflammatory drugs would be expected to have a similar effect to that of dopamine antagonists as prostaglandins tend to facilitate release of noradrenaline ${ }^{17} ;$ in the presence of an opiate and a non-steroidal anti-inflammatory drug, release of catecholamines falls, promoting the proconvulsant properties of the opiate. The $\delta$ receptors, which are proconvulsant and not subject to tolerance, coexist with $\mu$ receptors within the spinal cord. ${ }^{18}$

Cerebral secondary tumours cannot be discounted as a cause of or as being related to myoclonus. They are unlikely, however, to be the main cause of all of the cases of myoclonus in our study for the following reasons: symptoms were similar among the patients, the pattern was relatively long and unchanging, and episodes were temporally related to the dose of morphine and route of administration. Also, the epileptiform seizures arising from cerebral secondary tumours generally respond to anticonvulsants.

If our patients are representative it may be possible to treat myoclonus by changing palliative treatment. Reducing the total daily dose of opiate may reduce or stop the myoclonus: several of the patients related the onset of myoclonus and any subsequent loss of symptoms to increases or decreases in the dose of opiate. Overall, however, reducing the dose may have limited success in the light of the wide range of plasma concentrations over which myoclonus occurred. Ideally, it seems that psychotropic drugs should be stopped if possible; we are planning a trial to test this theory. Alternative antinauseant or adjuvant drugs could be used: domperidone is considered not to cross the blood-brain barrier, ${ }^{19}$ although it was taken as the only antiemetic by one of the patients with myoclonus (case 12), or alternatively steroids could be used as adjuvant agents ${ }^{20}$ rather than phenothiazines. Potent non-steroidal anti-inflammatory drugs could be reserved for patients with bony secondary tumours or with another clinical indication such as inflammatory joint disease: the onset of myoclonus was clearly related to the introduction of indomethacin or piroxicam in one of the patients. In our experience, anticonvulsants and baclofen are unsuccessful in controlling myoclonus. Frenk also found anticonvulsants unsuccessful for this purpose, ${ }^{15}$ although large doses of phenobarbitone have been reported to control terminal symptoms. ${ }^{3}$ Interestingly, steroids may be used to control myoclonus in hypsarrhythmia. ${ }^{21}$

We conclude that myoclonus with high doses of morphine is more likely to occur in patients taking antidepressant and antipsychotic drugs as antiemetics or adjuvant agents or non-steroidal anti-inflammatory drugs for additional analgesia. In patients who develop myoclonus substituting alternative adjuvant treatment in place of drugs that interact may be the most appropriate approach.

This study was supported by the Cancer Foundation of Western Australia. We thank the patients and their families and our nursing and medical colleagues who helped with this study.

1 Kaiko RF, Foley KM, Grabinski PY, et al. Central nervous system excitatory effects of meperidine in cancer patients. Ann Neurol 1983:13:180-5.

2 Hochman MS. Merperidine-associated myoclonus and seizures in long-term hemodialysis patients. Ann Neurol 1983;14:593.

3 Dunlop RJ. Is terminal restlessness sometimes drug induced? Palliative Medicine 1989;3:65-6.

4 Logan BK, Oliver JS, Smith H. The measurement and interpretation of morphine in blood. Forensic Sci Int 1987;35:189-95.

5 Berkowitz BA. The relationship of pharmacokinetics to pharmacological activity; morphine, methadone and naloxone. Clin Pharmacokinet 1976; 1:219-30.

6 Osborne R, Jocl S, Trew D, Slevin M. Analgesic activity of morphine-6lucuronide Lancet 1988;: 828.

7 Hanks GW, Hoskin PJ, Aherne GW, Turner P, Poulain P. Explanation for potency of repeated oral doses of morphine? Lancet 1987;ii:723-5.

8 Anderson RJ, Chung H-M, Kluge R, Schrier RW. Hyponatremia: a prospective analysis of its epidemiology and the pathogenetic role of vasopressin. tive analysis of its epidemiology

9 Reddy SVR, Maderdint JL, Yaksh TL. Spinal cord pharmacology of adrenergic agonist-mediated anti-nociception. 7 Pharmacol Exp Ther 1980 213:525-33

10 Yaksh TL, Wilson PR. Spinal serotonin terminal system mediates antinociception. I Phurmacol Exp Ther 1979;208:446-53.

11 Rang HP, Dale MM. Pharmacologv. Edinburgh: Churchill Livingstone, 1987:504.

12 Duggan AW, North RA. Electrophysiology of opioids. Pharmacol Rev 1984;35:219-81.

13 Curtis DR, Duggan AW. The depression of spinal inhibition by morphine. Agents Actions 1969:1:14-9.

14 Glavina MJ, Robertshaw R. Myoclonic spasms following intrathecal morphine. Anaesthesia 1988;43:389-90.

15 Frenk H. Pro- and anti-convulsant actions of morphine and the endogenous opioids: involvement and interactions of multiple opiate and non-opiate systems. Brain Res 1983;6: 197-212.

16 Dzoljic MR, Lely AJ vd, Mourik JBA v. Enkephalin-induced myoclonic twitches blocked by ergometrine and potentiated by haloperidol. Psychopharmacology 1979;66:111-6.

17 Leslie JB, Watkins WD. Eicosanoids in the central nervous system. Neurosurg 1985;63:659-68.

18 Yaksh TL. Spinal opiate analgesia; characteristics and principles of action Pain 1981;11:293-364.

19 Brogden RN, Carmine AA, Heel RC, Speight TM, Avery GI. Domperidone. A review of its pharmacological activity, pharmacokinetics and therapeutic efficacy in the simptomatic treatment of chronic dyspepsia and as an antiemetic. Drugs 1982;24:360-400.

20 Lowenthal RM. Jestrimski KW. Corticosteroid drugs: their role in oncological practice. Med f Aust 1986;144:81-5.

21 Eadie MJ. Which anticonvulsant drug? Drugs 1979;17:213-8. 